\title{
Increased expressed emotion in patients with psoriasis
}

\author{
Sibel Berksoy Hayta ${ }^{1}$, Rukiye Güner ${ }^{1}$, Melih Akyol' ${ }^{1}$, Funda Albayrak², Nesim Kuğ ${ }^{3}$, Sedat Özçelik ${ }^{1}$ \\ ${ }^{1}$ Department of Dermatology, School of Medicine, Cumhuriyet University, Sivas, Turkey \\ ${ }^{2}$ Dermatology Clinic, Medicalpark Hospital, Tokat, Turkey \\ ${ }^{3}$ Deparment of Psychiatry, School of Medicine, Cumhuriyet University, Sivas, Turkey
}

Neuropsychiatria i Neuropsychologia 2018; 13, 1: 9-16

\author{
Address for correspondence: \\ Ass. Prof. Sibel Berksoy Hayta \\ Department of Dermatology, School of Medicine \\ Cumhuriyet University \\ 58140 Sivas, Turkey \\ e-mail: drberksoy@gmail.com \\ phone: +903462581200
}

\section{Abstract}

Aim of the study: The aim of this study was to determine whether patients with psoriasis are affected by expressed emotion in their family environment.

Material and methods: Participants included 62 patients with psoriasis and 83 healthy controls and their biological parent, wife or husband, or adult child as a key relative. Sociodemographic data were recorded. Psoriasis area severity index was used to evaluate psoriasis severity. Hamilton depression and anxiety scales and the Expressed Emotion Questionnaire form were used to evaluate depression, anxiety, and expressed emotion.

Results: The levels of expressed emotion and its subgroups in the patient group were higher than in the group of healthy controls $(p<0.05)$. Gender, disease duration, disease severity, and key relatives did not affect the levels of expressed emotion (LEEtotal) in the patients with psoriasis $(p>0.05)$. The LEEtotal of those with low educational level in the patient group was statistically significantly higher than those with higher educational level $(\phi<0.05)$. There was no correlation between the presence depression or anxiety and expressed emotion $(p>0.05)$. There was a negative correlation between age and the levels of expressed emotion in the patient group $(p<0.05)$. There was a negative correlation between age and intrusiveness in healthy controls $(p<0.05)$.

Conclusions: Although decreasing with age, expression of emotion in patients with psoriasis is high, and psychosocial support should be provided to these patients.

Key words: psoriasis, expressed emotion, dermatology.

\section{Introduction}

Psoriasis is a chronic inflammatory disease that affects $2 \%$ of the world's population (Akyol et al. 2016). It is an accepted fact that mental-social problems are effective at the onset and exacerbation of many skin diseases or mental problems occur secondarily in chronic skin diseases (Kumbasar and Yllmaz 2005). Because psoriasis is a chronic disease and there is not any treatment to provide a full cure yet, besides physical complaints, it is also associated with many psychological problems such as decreased self-confidence, sexual dysfunction, anxiety, depression, and suicidal ideation. Patients with psoriasis may feel like they are stigmatised because of their appearance, and therefore they may feel embarrassed. Other people may believe that psoriasis is an infectious disease and they may show negative reactions to patients with psoriasis. After this experienced negative reaction, the general condition disorder caused by the disease and the stress developing depending on the disease in patients with psoriasis also increases even more (Chen $e t$ al. 2014). The relationship between psychological events and psoriasis is bi-directional, and the effect of psychological factors on its onset and exacerbation is a generally accepted characteristic. Additionally, the psychological disorders caused by symptoms that are present on their skins also cause an important problem in these patients (Aydemir and Sukan 2008). The treatment of psychological disorders caused by psoriasis may be more important and difficult than the treatment of physical disorders. Psychological interventions can be made to the patients with psoriasis with both psychological and educational programs. The necessity for such training programs has recently been stated (Chen et al. 2014).

Expressed emotion mainly covers criticism, hostility, and excessive interest and is used to 
assess the emotional atmosphere of the home environment (Barrowclough et al. 2005). Chronic diseases can affect the whole family. While the negativities in the family relationships affect the patient negatively, the problems experienced by the patient negatively affect the family relationships. Establishing a healthy family environment will affect the prognosis of the disease positively (Öksüz 2017; Dominguez-Martinez 2017; Erol and Yazıcı 2000).

If expressed emotion is addressed as a measure of reciprocal social support, its clinical use is more comprehensive and not limited to psychiatric disorders alone. Expressed emotion is an important and powerful determinant of relapses in some psychiatric and physiological disorders. Recently many studies have revealed the relationship of expressed emotion with some diseases such as depression, obsessive compulsive disorders, bipolar disorders, attention deficit and hyperactivity disorder, epilepsy, diabetes, asthma, eating disorders, fibromyalgia apart from schizophrenia and the relationship between high expressed emotion and diseases (Öksüz 2017; DominguezMartinez 2017; Erol and Yazıcı 2000; Nelis et al. 2011; Sin et al. 2017; Hoste and le Grange 2008; Gartland and Day 1999; Kyriacou et al. 2008; Christiansen et al. 2010; Di Paola 2010; Hastings and Lloyd 2007; Hayta et al. 2016; Wearden et al. 2000; Sadath et al. 2017; Cherry et al. 2017; Hooley 2007; Watts 2007; Broderick et al. 2005). These studies gave rise to the opinion that the expressed emotion can be used effectively in clinical follow-up of diseases associated with psychiatric disorders such as psoriasis.

There are many scales to assess the quality of life of patients with psoriasis. The questions in these scales are prepared to determine the effects of illness on some aspects of daily life activities, social relationships, and sexual lives of patients. In addition, the relationship of psoriasis with depression and anxiety has been examined in the literature (Akyol et al. 2016; Kaçar 2007). However, there are no studies in the literature indicating whether or not patients with psoriasis are affected by the expressed emotion in the family environment. The aim of this study was to determine whether patients with psoriasis are affected by expressed emotion in their family environment.

\section{Material and method}

\section{Case selection}

Before starting the study, the necessary Ethics Committee (2008-12/3) approval was ob- tained. Sample size estimation for the present study with $95 \%$ confidence interval was made by power analysis, and 83 healthy individuals and 62 patients, who applied to dermatology outpatient clinic, signed the informed consent form, were diagnosed histopathologically and clinically with psoriasis, and the patients' relatives with whom they were living for at least six months, they consider important in their relations, and they identified as key relatives were included in the study.

\section{Inclusion criteria of the study}

The inclusion criteria were determined as being older than 18 years, being literate, having never been diagnosed with depression and/ or anxiety before for the patient group. For the control and key relative groups the inclusion criteria were determined as not having any known health problem, being older than 18 years, and being literate.

Sociodemographic data and the disease-related characteristics of the patients, the control group, and their relatives were recorded in the prepared data form. Severity of the disease in the patients with psoriasis was calculated and recorded with the Psoriasis Area and Severity Index (PASI)

\section{Scales}

\section{Level of Expressed Emotion (LEE) scale}

The Level of Expressed Emotion (LEE) scale was applied to the patients and the control group. The scores calculated for the LEE scale were recorded.

The LEE scale is a self-assessment tool developed by Cole and Kazarian (1988) to assess the emotional state between the patient and a person who is important for the patient, and to rank some characteristics of the relationship. The items are marked as true or false by considering the relationships of the patients and the person who is in the position of key relative within the last three months. It includes 60 items in total. It is composed of 15-item subscales of Intrusiveness "I", Emotional response "E", Attitude toward illness "A", and Tolerance/Expectation "T". While the subscale scores range from 0 to 15 , the total score ranges from 0 to 60 . The Turkish adaptation of the scale and its validity-reliability study were carried out by Berksun (1992). The higher the score, the higher the expressed emotion level of the family (Di Paola et al. 2010; Cole and Kazarian 1988; Erbinç et al. 2001). 
Table 1. The distribution of age, gender, educational status, and key relatives among the groups

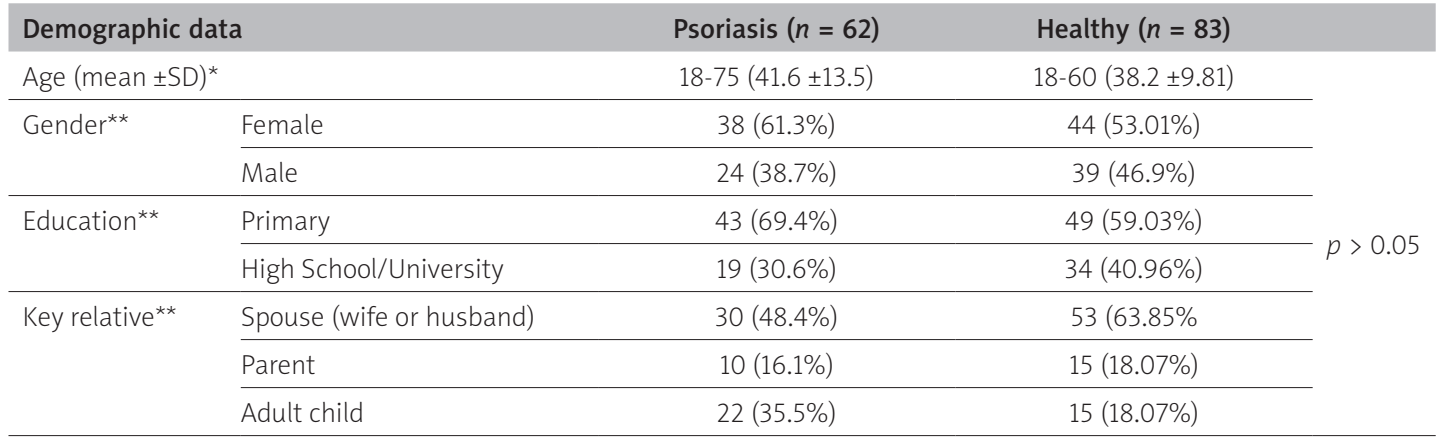

*Mann-Whitney $U$ test, ${ }^{* *}$ Chi-square test

\section{Depression and anxiety scales}

Patients with psoriasis were evaluated by the psychiatry clinic for the presence of depression and anxiety using the Hamilton Depression Rating Scale (HAM-D) and Hamilton Anxiety Rating Scale (HAM-A), which have Turkish validity and reliability.

\section{HAM-D}

It is a 17-question form applied by the clinician to patients with depressive symptoms to measure the level of the depression and the severity change. The questions can be scored between 0 and 4 , and the sum of them gives the actual score. The highest score is 53 . It was developed by Hamilton and structured by Williams (1978). Its Turkish adaptation and validity-reliability studies were conducted by Akdemir et al. (1996) (Aydemir and Köroğlu 2000).

\section{HAM- $A$}

It is a 14-question form that is applied by the clinician to healthy or psychiatric patient groups and is used determine the anxiety level and symptom distribution and to measure the severity change and questions both psychological and physical symptoms. While the score for each item ranges from 0 to 4 , the total score for the scale ranges from 0 to 56. It was structured by Hamilton (1959). Its Turkish adaptation and validity and reliability studies were conducted by Yazıcı et al. (1998) (Aydemir and Köroğlu 2000).

\section{Statistical analysis}

The data of the study were evaluated by being uploaded in version 23.0 of the SPSS (Statistical Package for Social Sciences) program. The Kolmogorov-Smirnov test was applied to test the normality of the distribution of data. Accordingly, the Mann-Whitney $U$ test was used to determine the difference between the groups. For a comparison of more than two group means, one-way analysis of variance (ANOVA) was used. Chi-square test was used to determine the difference in terms of the education and key relatives in both groups. Spearman correlation analysis was used to determine the relationship between age and LEE scores. The value of $p<0.05$ was accepted as significant.

\section{Results}

Table 1 shows the age, gender, educational status, and key relative distribution of the patients included in the study.

When psoriasis and healthy control groups were compared, it was determined that $\mathrm{LEE}_{\text {total }}$ scores of sub-groups I, E, and A were statistically significantly higher in the patient group compared to the healthy controls $(p=0.00, p=0.00$, $p=0.002, p=0.00$, respectively) (Fig. 1); the difference among the groups for subgroup $\mathrm{T}$ was statistically insignificant $(p=0.096)$.

When the patient and healthy control groups were evaluated in terms of female gender, $\mathrm{LEE}_{\text {total }}$ and scores of subgroups I, E, and A were found to be statistically significantly higher in the patient group compared to the healthy controls $(p=0.002, p=0.001, p=0.009, p=0.002$, respectively). There was no statistically significant difference between the groups in terms of subgroup $\mathrm{T}$ scores $(p=0.086)$.

When the patient and healthy control groups were evaluated in terms of male gender, $\mathrm{LEE}_{\text {total }}$ and scores of subgroup I and A were found to be statistically significantly higher in the patient group $(p=0.013, p=0.001, p=0.013$, respectively). No statistically significant difference was found among the groups in terms of subgroups $\mathrm{E}$ and $\mathrm{T}(p=0.059$ and $p=0.709$, respectively).

When the patient group was evaluated, no statistically significant difference was found 

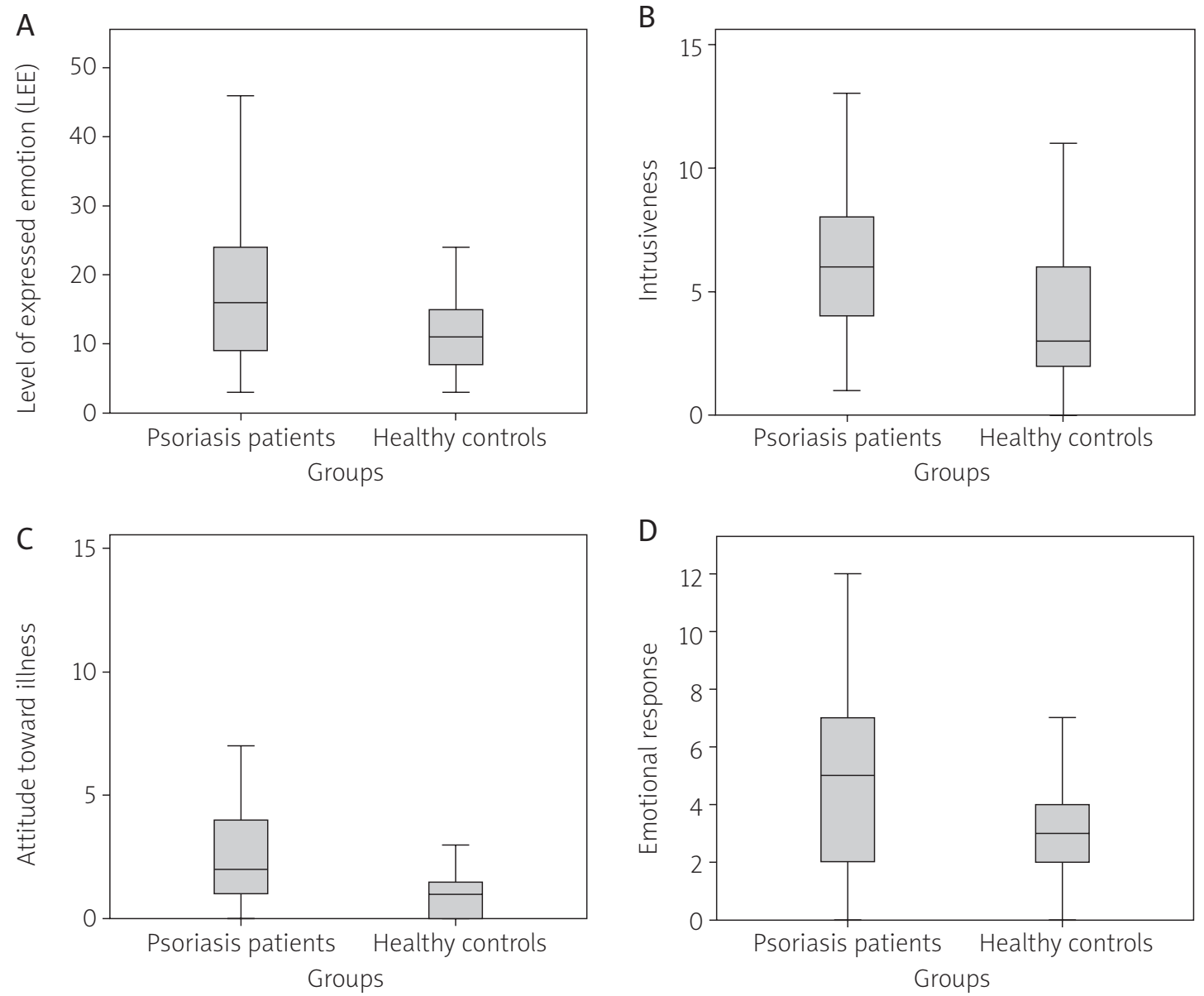

Fig. 1. Comparison of mean level of expressed emotion (A) and scores of subgroups Intrusiveness (B), Emotional response, (C) in patient and control groups, (D) and Attitude toward illness

between men and women in terms of LEE $_{\text {total }}$ and subgroup scores $(p>0.05)$.

While there was a statistically significant and negative correlation between the age and $\mathrm{LEE}_{\text {total }}$, and scores of subgroups $\mathrm{E}, \mathrm{A}$, and $\mathrm{T}$ in the patient group $(p=0.01, r=-0.317 ; p=$ $0.04, r=-0.257 ; p=0.03, r=-265 ; p=$ $0.03, r=-0.274$, respectively), a significant difference was not found for subgroup I $(p=$ $0.117, r=0.201)$. While there was a significant and negative correlation between age and subgroup I ( $p=0.01, r=-0.281)$, no statistically significant correlation was observed between age and $\mathrm{LEE}_{\text {total }}$ and other subgroup scores in healthy controls $(p>0.05)$ (Fig. 2).

No statistically significant correlation was found between the $\mathrm{LEE}_{\text {total }}$ and subgroup scores and the depression and anxiety scores in the group $(p>0.05)$.

The patient group was divided into two groups according to PASI scores as mild (PASI $<10$ ) and moderate-severe (PASI $\geq 10)$. When the mild and moderate-severe cases were compared in terms of $\mathrm{LEE}_{\text {total }}$ and subgroup scores, no statistically significant difference was found $(p>0.05)$.

According to educational status, patients and healthy controls were examined in two groups as primary school and high school-university graduates. No statistically significant difference was found in terms of the educational level of the patient and control groups $(p=0.22)$. It was determined that the $\operatorname{LEE}_{\text {total }}(p=0.01)$ and scores of subgroups $\mathrm{E}(p=0.02), \mathrm{A}(p=0.02)$, and $\mathrm{T}(p=0.003)$ of those with low educational level (primary school) in the patient group was statistically significantly higher than those with higher educational level (high school-university). No statistically significant difference was found in the scores of subgroup I $(p=0.70)$. No statistically significant difference was found between the educational level and $\mathrm{LEE}_{\text {total }}$ and LEE subgroups in healthy controls $(p>0.05)$.

There was no statistically significant difference in the scores of the $\mathrm{LEE}_{\text {total }}$ and LEE subgroups in the patient group when the key relative was a spouse or parent or an adult child $(p>0.05)$. 

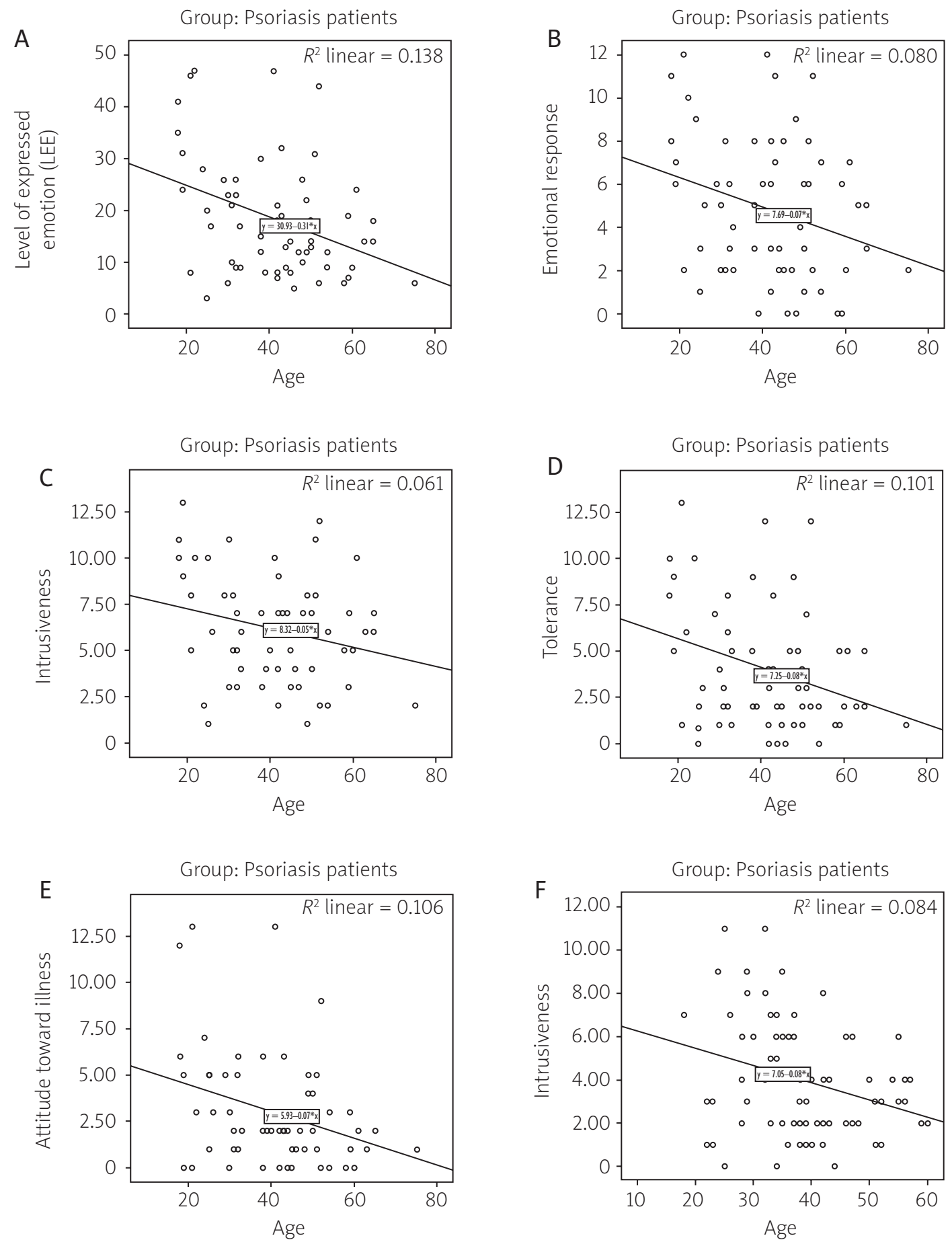

Fig. 2. Correlation between the age and LEEtotal and LEE subgroup scores in patients and healthy controls

The duration of the disease was examined in three groups as the last one year, 1-5 years, and more than 5 years in the patient group, and no statistically significant difference was found between LEE and subgroup scores $(p>0.05)$.

\section{Discussion}

It has been known for years that stress is an important factor in the onset or exacerbation of psoriasis. Stress can be both an outcome and a trigger of psoriasis (Griffits and Richards 2001). The fact that the disease has an uncertain development, the recurrences cannot be predicted and prevented in advance, and there is still no definite treatment causes a great deal of stress in patients with psoriasis (Kumbasar and Yllmaz 2005; Pişkin 2005; Richards et al. 2005). Psoriasis can contribute to the development of psychopathology by negatively affecting the body image, 
self-confidence, identity, life goals, ego integrity, social, family, and environmental relations of the patient (Kumbasar and Yllmaz 2005).

Expressed emotion is evaluated as a measure of emotional quality of family life and the emotional atmosphere of the home environment (Hoste and le Grange 2008; Norman and Malla 1993). Expressed emotion is also defined as the determinant of the family's perspective and attitude toward the patient and is considered as an important factor that can affect the prognosis of the disease positively or negatively in chronic diseases (Devaramane et al. 2011).

Highly expressed emotion is not a static structure but a reaction style that develops over time. High expressed emotion perception can lead to constant stress in the patient (Erol and Yazıcı 2000). High expressed emotion includes high severity criticism against the patient, hostility, avoidance, or excessive emotional care (Sadath et al. 2017). It has been shown in the studies that expressed emotion may influence the disease in various patient groups or the current disease may affect the expressed emotion (Gartland and Day 1999; Kyriacou et al. 2008; Sadath et al. 2017).

It can be asserted that patients with psoriasis displayed a higher expression emotion than the healthy control group, but this was not associated with disease severity.

In the study by Hale et al. (2007), no statistically significant difference was found between the $\mathrm{LEE}_{\text {total }}$ scores and age and gender. In another study, even though $\mathrm{LEE}_{\text {total }}$ scores of women were found to be slightly higher than $\operatorname{LEE}_{\text {total }}$ scores of men, the difference between the genders was not found to be statistically significant. In the same study, no statistically significant difference was found between the ages (Gerlesma et al. 1992). It was concluded from the results of both studies that age and gender did not affect the LEE $_{\text {total }}$ score in both adults and adolescents (Hale et al. 2007; Gerlesma et al. 1992). In the present study, it was found that gender did not affect expressed emotion in the patient group, but age showed a negative correlation. Recent studies have shown that women report more physical disorders in many diseases and give lower quality of life scores. It has been seen that women identify more pain, illness symptoms, and psychological problems (Sampogna et al. 2006; Wolkenstein 2006). In the study conducted by Sampogna et al. (2006), in which psoriasis patients were classified as below or over 65 years of age, they reported that anxiety and depression were seen more often in elderly women, their life quality was worse, and this was associated with the fact that women had higher body perceptions and regarded their appearance more than men. In addition, it was also reported that its effect on the quality of life in patients with psoriasis decreased with age. It was shown that the elderly were highly affected by psoriasis physically and young people were affected more psychosocially by the disease (Wolkenstein 2006). In the present study, it was also observed that expressed emotion decreased with increased age in the patients. Additionally, intrusiveness also decreased with increased age in our healthy group. The learning and acceptance of the basic characteristics of the disease, such as clinical picture and treatment outcomes, by patients and other family members over time, can be considered as the reasons for this decrease.

According to the results of the present study, patients with psoriasis perceived high expressed emotion in both genders. Being male or female did not affect the expressed emotion perception. Nevertheless, while women perceived their families as being intrusive, overreactive, and having negative attitudes towards their illness in the case of disease, the perception in men focused on interventionism. The defined roles of males and females in society can be a reason for the difference in subgroups in terms of expressed emotion.

It was reported in the studies that increased educational level affected the expressed emotion positively by decreasing stress about the disease, easing coping with stress, and perceiving the chronic illness as a part of everyday life in different patient groups (Wolkenstein 2006; Honig et al. 1997; Uehara et al. 2001). According to our results, the low educational level led to a higher level of expressed emotion. When subgroups were evaluated, those with low educational levels had overreactive, negative attitudes towards disease, intolerance, and high expectation perception. Lower expressed emotion can be associated with the fact that the group with high educational level had more knowledge and comprehension about the disease-related issues such as knowing that the disease is contagious, and usage of the medications at correct time and dose.

In the present study, the family member with the primary interaction of the patient was selected as the key relative, and the key relationship status did not affect the expressed emotion.

In the study conducted by Hale et al. (2007), with paediatric patients and their parents, they found a correlation between the LEE scores of the patients with their depression and anxiety scores. The results of our study showed that the 
presence of anxiety or depression did not affect the expressed emotion in adult psoriasis patients.

Limitations of the present study are that a general assessment of intra-family relationships was not conducted, and the relationship between expressed emotions, which is a dynamic measure with the disease relapse, was not evaluated. For this purpose, a prospective dynamic study is required.

Consequently, the effect of the family environment on the individuals living in the family like other social environments is known. Because psoriasis is a chronic disease it can affect the intra-family relationships of the person, and the disease itself can be affected by family interaction. It can be asserted that the expressed emotion in patients with psoriasis is due to the physical lesions triggered by emotional stresses. Family environment should be considered carefully, especially for patients with psoriasis, who are young or have low educational level. It should be kept in mind that family conflicts may cause an adverse effect on the course of the disease, as a constant source of stress. Expressed emotion is high in psoriasis. Therefore, the LEE scale should be used in evaluating the family environment, and patient-family interaction of psoriasis patients and psychosocial support should be provide in cases with high expressed emotion.

\section{References}

1. Akyol M, Alper S, Atakan N, et al. Türkiye psoriasis tedavi kılavuzu-2016. Türkderm 2016; 50 (Suppl.): 1-62.

2. Aydemir EH, Sukan MY. Psychosomatic factors and psychologic status in psoriatic patients and approach to the psoriatic patients. Türkderm 2008; 42: 26-30.

3. Aydemir Ö, Köroğlu E (Eds.). Psikiyatride kullanılan klinik ölçekler. Hekimler Yayın Birliği, Ankara 2000.

4. Barrowclough C, Ward J, Wearden A, et al. Expressed emotion and attributions in relatives of schizophrenia patients with and without substance misuse. Soc Psychiatry Psychiatr Epidemiol 2005; 40: 884-891.

5. Broderick JE, Junghaenel DU, Schwartz JE. Written emotional expression produces health benefits in fibromyalgia patients. Psychosom Med 2005; 67: 326-334.

6. Chen Y, Xin T, Cheng AS. Evaluating the effectiveness of psychological and/or educational interventions in psoriasis: a narrative review. J Dermatol 2014; 41: 775-778.

7. Cherry MG, Taylor PJ, Brown SL, et al. Guilt, shame and expressed emotion in carers of people with long-term mental health difficulties: A systematic review. Psychiatry Res 2017; 249: 139-151.

8. Christiansen H, Oades RD, Psychogiou L, et al. Does the cortisol response to stress mediate the link between expressed emotion and oppositional behavior in Attention-Deficit/Hyperactivity-Disorder (ADHD)? Behavioral and Brain Functions 2010; 6: 45-56.

9. Cole JD, Kazarian SS. The level of expressed emotion scale: a new measure of expressed emotion. J Clin Psychol 1988; 44: 392-397.
10. Devaramane V, Pai NB, Vella SL. The effect of a brief family intervention on primary carer's functioning and their schizophrenic relatives levels of psychopathology in India. Asian J Psychiatr 2011; 4: 183-187.

11. Di Paola F, Faravelli C, Ricca V. Perceived expressed emotion in anorexia nervosa, bulimia nervosa, and binge-eating disorder. Comprehensive Psychiatry 2010; 51: 401-405.

12. Di Paola F, Faravelli C, Ricca V. Perceived expressed emotion in anorexia nervosa, bulimia nervosa, and binge-eating disorder. Compr Psychiatry 2010; 51: 401-405.

13. Dominguez-Martinez T, Medina-Pradas C, Kwapil TR, et al. Relatives expressed emotion, distress and attributions in clinical high-risk and recent onset of psychosis. Psychiatry Res 2017; 247: 323-329.

14. Erbinç S, Çetin M, Başoğlu C, et al. Research of family functionality, social support and expression of emotion in schizophrenic patients and their families. Anatolian J Psychiatry 2001; 2: 5-14.

15. Erol A, Yazıcı F. Ilk epizod şizofreni ve psikotik özellikli manide: Duygu dışavurumunun karşılaştırılması. Dicle Tıp Dergisi 2000; 27: 7-15

16. Gartland HJ, Day HD. Family predictors of the incidence of children's asthma symptoms: expressed emotion, medication, parent contact, and life events. J Clin Psychol 1999; 55: 573-584.

17. Gerlesma C, Lubbe PM, Nieuwenhuizen C. Factor analiysis of the level of expressed emotion scale, a questionnaire intended to measure 'perceived expressed emotion'. Brit J Psychiatry 1992; 160: 385-389.

18. Griffits CEM, Richards HL. Psychological influences in psoriasis. Clin and Exp Dermatol 2001; 26: 338-342.

19. Hale WW, Raaijmakers QAW, Gerlsma C, et al. Does the level of expressed emotion (LEE) questionnaire have the same factor structure for adolescent as it has for adults? Soc Psychiatry Psychiatr Epidemiol 2007; 42: 215-220.

20. Hastings RP, Lloyd T. Expressed emotion in families of children and adults with intellectual disabilities. Ment Retard and Dev Disabil Res Rev 2007; 13: 339-345.

21. Hayta E, Mert DG, Aydınkal Semiz E, et al. Expressed emotion in fibromyalgia: Contribution of spouses 'attitude and patients' perception to clinical presentation of fibromyalgia. Cumhuriyet Medical Journal 2016; 38 : 322-331.

22. Honig A, Hofman A, Rozendaal N, et al. Psycho-education in bipolar disorder: effect on expressed emotion. Psychiatry Res 1997: 72; 17-22.

23. Hooley JM. Expressed emotion and relapse of psychopathology. Annu Rev Clin Psychol 2007; 3: 329-352.

24. Hoste RR, le Grange D. Expressed emotion among white and ethnic minority families of adolescents with bulimia nervosa. Eur Eat Disord Rev 2008; 16: 395-400.

25. Kaçar N, Ergin Ş, Erdoğan ŞB. Psoriasisli hastalarda yaşam kalitesi. Türkderm 2007; 41: 117-120.

26. Kumbasar H, Yılmaz A. Psychoneuroimmunologic mechanisms in pathogenesis of psoriasis and effects of disease at quality of life. Turkiye Klinikleri J Int Med 2005; 1: 50-55.

27. Kyriacou O, Treasure J, Schmidt U. Expressed emotion in eating disorders assessed via self-report: an examination of factors associated with expressed emotion in carers of people with anorexia nervosa in comparison to control families. Int J Eat Disord 2008; 41: 37-46.

28. Nelis SM, Rae G, Liddell C. The level of expressed emotion scale: A useful measure of expressed emotion in adolescents? J Adolescence 2011; 34: 311-318.

29. Norman RMG, Malla AK. Stressful life events and schiophrenia. Br J of psychiatry 1993; 162: 161-174. 
30. Öksüz E, Karaca S, Özaltın G, et al. The effects of psychoeducation on the expressed emotion and family functioning of the family members in first-episode schizophrenia. Community Ment Health J 2017; 53: 464-473.

31. Pişkin G. Psoriyazisin patogenezi. Türkiye Klinikleri Dermatoloji 2005; 1: 5-12.

32. Richards HL, Ray DW, Kirby B, et al. Response of the hy pothalamic-pituitary-adrenal axis to psychological stres in patients with psoriasis. Br J Dermatol 2005; 153: 1114-1120.

33. Sadath A, Muralidhar D, Varambally S, et al. Do stress and support matter for caring? The role of perceived stress and social support on expressed emotion of carers of persons with first episode psychosis. Asian J Psychiatr 2017; 25: 163-168.

34. Sampogna F, Chren MM, Melchi CF, et al. Age, gender, quality life and psychological distress in patients hospitalized with psoriasis. Br I Dermatol 2006; 154: 325-331.

35. Sin J, Gillard S, Spain D, et al. Effectiveness of psychoeducational interventions for family carers of people with psychosis: A systematic review and meta-analysis. Clin Psychol Rev 2017; 56: 13-24.

36. Uehara T, Kawashima Y, Goto M, et al. Psychoeducation for the families of patients with eating disorders and changes in expressed emotion: A preliminary study. Compr Psychiatry 2001: 42; 132-138.

37. Watts M. High expressed emotion: precipitating relapse in substance misuse disorders. Br J Nurs 2007; 16: 1396 1398.

38. Wearden AJ, Tarrier N, Barrowclough C, et al. A review of expressed emotion research in health care. Clin Psychol Rev 2000; 20: 633-666.

39. Wolkenstein P. Living with psoriasis. J Eur Acad Dermatol Venerol 2006; 20: 28-32 